\title{
Custos de reciclagem de pavimentos de concreto e seu potencial econômico na realidade brasileira
}

\author{
José Tadeu Balboํㅜ, Ricardo Cruvinel Dornelas²
}

\begin{abstract}
Resumo: Os custos de produção de agregados reciclados de concretos de antigos pavimentos devem ser contextualizados nas obras de pavimentação rodoviária no país. Valores fornecidos em tabelas de serviços para vias urbanas podem não refletir as condições específicas da demolição em rodovias. Também, preços operados em outros países são afetados pela tecnologia de reciclagem empregada, que não é aquela que tem sido considerada no Brasil. Neste artigo são determinadas as razões unitárias de produção relacionadas à demolição, carga, transporte e britagem de pavimentos de concreto removidos de pistas de duas rodovias brasileiras. Com base nos resultados pôde-se verificar um acréscimo de $50 \%$ no custo final do agregado reciclado em relação ao agregado virgem, resultando em acréscimo de cerca de $20 \%$ nos custos de produção de concretos para pavimentação. O potencial brasileiro de produção desses agregados reciclados a partir de pavimentos de concreto deteriorados é limitado o que pode ser um fator estagnante para o emprego da tecnologia no país.
\end{abstract}

Palavras-chave: agregado reciclado, pavimento de concreto, custos unitários, produtividade.

Abstract: The costs for the production of recycled aggregate concrete from old concrete pavements must be contextualized in the works for road paving in the country. Values provided for urban roads works may not reflect the specific conditions of the demolition on highways. Also, prices operated in other countries are affected by the recycling technology used abroad that is not what has been used in Brazil. In this article are considered the unit production rates related to demolition, loading, transportation and crushing of concrete pavement removed from two Brazilian highways. Based on the results it was verified an increase of $50 \%$ in the final cost of the recycled aggregate compared to virgin aggregate, resulting in an increase of about $20 \%$ in production costs of concretes for paving. The Brazilian potential of production of such recycled aggregates is limited what can be a stagnant factor for the use of this technology in the country.

Keywords: recycled aggregate, concrete pavement, unit costs productivity.

\section{INTRODUÇÃO}

O setor rodoviário brasileiro enfrenta uma crise anunciada desde o principio dos anos 1980. Ela possui duas componentes que paralelamente vêm se agravando década após década. De um lado, com dados do ano 2012 sabe-se que existe uma extensão total pavimentada de rodovias e estradas rurais de $219.847 \mathrm{~km}$ diante de uma extensão total de vias municipais, estaduais e federais de $1.584 .103 \mathrm{~km}$ (DNIT, 2012); ou seja, possuímos uma demanda de mais de 1,3 milhões de quilômetros de estradas carentes de pavimentação. Este apelo não é nada fácil de ser atendido, mesmo porque, do total, $1.261 .745 \mathrm{~km}$ configuram estradas municipais, onde a disponibilidade de recursos frente a outras demandas sociais urgentes, para pavimentação, é muitas vezes inexistente.

O segundo aspecto é concernente à qualidade das estradas e vias pavimentadas. Na pesquisa anual da Confederação Nacional do Transporte (CNT, 2014), por exemplo, apenas $37,9 \%$ da parcela de $62,1 \%$ das vias pavimentadas do país que foram objeto da avaliação $(98.475 \mathrm{~km})$, apresentavam condições de pavimentação satisfatórias; o restante dos trechos avaliados apresentava condição de rolamento de deficiente até péssima (neste caso, atingindo 29,3\% da malha rodoviária avaliada, que exigiria reconstrução e não simples serviços de conservação e manutenção).

\footnotetext{
1 José Tadeu Balbo, Universidade de São Paulo, EPUSP.

(jotbalbo@usp.br)

2 Ricardo Cruvinel Dornelas, Universidade Federal de Goiás, Regional

Catalão. (ricardo.dornelas@catalao.ufg.br)

Manuscrito recebido em 16/09/2014 e aprovado para publicação em 16/06/2015.

Este artigo é parte de TRANSPORTES v. 23 , n. 2, 2015. ISSN: 2237-1346 (online). DOI: 10.14295/transportes.v23i2.846
}

Não será possível superar as carências no Brasil, em matéria de infraestrutura viária, bem como é muito difícil atender a toda a demanda existente de novas construções, sem a consideração do uso racional de materiais reciclados a partir dos próprios pavimentos já existentes.

A reciclagem dos pavimentos de concreto, preferencialmente para a construção de novos pavimentos de concreto, é tecnicamente viável e ambientalmente desejável (Tseng, 2010). Do ponto de vista ambiental, ela evitaria o emprego de áreas para aterro e depósito de resíduos, contribuiria com a preservação de fontes de agregados naturais bem como reduziria os custos energéticos de exploração de matéria prima, causando eventualmente menor emissão de poeira e lançamento de $\mathrm{CO}_{2}$ para a atmosfera; também faria com que as usinas e empresas de concretagem pudessem evitar qualquer refugo de material inicialmente inservível endurecido (USDOT, 2004).

$\mathrm{O}$ emprego de concreto reciclado em pavimentos ocorreu em escala de uso na Europa, em especial na Alemanha, desde o início dos anos 1980, quando teve início grande parte das reconstruções das autoestradas construídas na década de 1930 (HALL, 2007). As principais dificuldades que levaram os alemães aos processos de reciclagem de pavimentos de concreto foram duas: a) a escassez de matéria prima virgem e seu custo devido às diretrizes ambientais de exploração de matérias virgens cada vez mais restritivas e; b) o custo de execução de bota-fora para grandes quantidades de reconstruções (WOLF e FLEISCHER, 2007). Por outro lado, culturalmente inclusive, na Alemanha se tinha uma experiência recorrente altamente positiva sobre o emprego de rodovias em concreto - cerca de $40 \%$ das vias pavimentadas na Alemanha eram em concreto na década de 1990 (BALBO, 2009). Tratava-se de uma apologia técnica do conceito europeu pós-guerra de "fazer novo com o 
BALBO, J.T.; DORNELAS, R.C.

Tabela 1. Principais estados e cidades com potencial de reciclagem de vias pavimentadas em concreto

\begin{tabular}{llllll}
\hline Estado & $\begin{array}{l}\text { Volume } \\
(\boldsymbol{m 3})\end{array}$ & $\mathbf{\%}$ & Cidade & $\begin{array}{l}\text { Volume } \\
(\boldsymbol{m 3})\end{array}$ & $\boldsymbol{\%}$ \\
\hline Pernambuco & 367.376 & 30,2 & Recife & 240.554 & 63.9 \\
Bahia & 20.592 & 1,7 & Belo Horizonte & 29.700 & 7.9 \\
Mato Grosso & 41.184 & 3,4 & Rio de Janeiro & 11.445 & 3.0 \\
Rio de Janeiro & 164.808 & 13,5 & Curitiba & 52.488 & 13.9 \\
São Paulo & 550.085 & 45,2 & Porto Alegre & 42.025 & 11.2 \\
Santa Catarina & 13.147 & 1,1 & & & \\
Rio Grande do Sul & 59.626 & 4,9 & & & \\
\hline Total & 1.216 .819 & 100 & Total & 376.212 & 100 \\
\hline \multicolumn{5}{c}{ (Fonte primária: TSENG e BALBO, 2013) } \\
\end{tabular}

usado", empregando as antigas placas de concreto como "jazidas" de agregados para a confecção de novo concreto para pavimentação. A utilização de agregados graúdos reciclados em camadas inferiores de pavimentos de concreto de duas camadas (revestimento em concreto de aproximadamente $26 \mathrm{~cm}$ em que os $7 \mathrm{~cm}$ superiores são construídos com agregados de melhor qualidade) é uma prática comum na Alemanha. Os agregados miúdos, muitas vezes não aproveitáveis $100 \%$ na reciclagem do concreto, obtidos poderiam ser utilizados em bases estabilizadas com cimento.

Nos Estados Unidos da América os agregados reciclados foram utilizados em misturas de concreto a partir da década de 1940 (ACPA, 2009). No caso do seu uso em pavimentos de concreto, as primeiras aplicações datam da década de 1970. Todavia, alguns casos iniciais de desempenho insatisfatório desencorajaram algumas agências rodoviárias estaduais a empregar tais técnicas, até que futuros estudos e experimentos trouxessem melhor luz às dificuldades observadas (DARTER, 1988; SNYDER et al., 1997). Em 1987, mais de 1.600 quilômetros de pistas com pavimentos de concreto já haviam sido recicladas nos EUA (Portland Cement Association, 1999).

O programa National Cooperative Highway Research Program dos EUA reportou os primeiros resultados de observações em campo sobre pavimentos rígidos de camada única contendo agregados reciclados construídos em Iowa, Michigan, Minnesota e Wisconsin entre 1981 e 1986. Depois disso ocorreram amplos estudos na Universidade de Minnesota (em 1997 e em 2006), bem como em estradas construídas em Connecticut, Kansas, Minnesota, Wisconsin e Wyoming nos anos 1980 (YRJANSON, 1989).

Dentro do espectro da reciclagem dos antigos pavimentos deteriorados, os pavimentos de concreto, ainda que representem um pequeno montante (em torno de $2 \%$ da rede pavimentada brasileira, segundo BALBO, 2009) de material em relação às superfícies pavimentadas, são objeto de interesse do ponto de vista de reciclagem, tanto em rodovias quanto em vias urbanas. Esse potencial é demonstrado na Tabela 1 em termos de rodovias e vias urbanas existentes. A pesquisa realizada desconsiderou os seguintes casos: vias urbanas ou rodovias construídas há menos de uma década, como por exemplo, as perimetrais de Porto Alegre e de $\mathrm{Cu}-$ ritiba; vias que sofreram tantos e sucessivos recapeamentos através das décadas que praticamente inviabilizam economicamente essa solução (a exemplo, podem ser citadas a Av. Brasil no Rio de Janeiro e as rodovias Anchieta e Anhanguera no Estado de São Paulo; também é o caso da grande maioria de vias urbanas das décadas de 40 e 50 recapeadas sucessivamente com misturas asfálticas em São
Paulo); pequenas extensões de vias, como em alguns casos urbanos no Distrito Federal e em Salvador (de acordo com informações obtidas); pavimentos em túneis e revestimentos em concreto sobre viadutos urbanos; aeroportos, portos e pisos industriais não considerados; terminais urbanos e rodoviários de ônibus.

As informações aqui sistematizadas foram obtidas por meio (de comunicação pessoal) das seguintes fontes confiáveis: junto à Prefeitura do Município de São Paulo; junto à Prefeitura Municipal de Porto Alegre; junto à Associação Brasileira de Cimento Portland (ABCP) em Recife; junto à $\mathrm{ABCP}$ no Rio de Janeiro; em documento publicado pela ABCP (2009). Muitos dos dados apresentados nessa publicação foram adequados às demais informações disponibilizadas. Na Tabela 1 são indicados os volumes de concreto de revestimento de pavimentos (placas) considerando as principais e mais relevantes rodovias brasileiras bem como os volumes de pavimentos em concreto nas mais importantes capitais. Observe-se que 1,5 milhões de $\mathrm{m}^{3}$ de agregado reciclado podem representar grosso modo $800 \mathrm{~km}$ de revestimento em concreto em vias de duas faixas de rolamento.

A reciclagem dos pavimentos de concreto, do ponto de vista econômico, poderia significar redução em custos totais de novos projetos, o que ficaria bastante fadado às condições de processamento dos materiais bem como de transporte, especialmente desse último, considerados ainda BDI sobre tais custos. Essas informações são difusas e muitas vezes incongruentes por não serem diretamente comparáveis; por exemplo, nos EUA o preço de venda de agregados reciclados a partir de concreto pode variar de 7 a 10 dólares americanos $/ \mathrm{m}^{3}$ para britados com diâmetros entre 50 e $75 \mathrm{~mm}$ e entre 25 e $38 \mathrm{~mm}$, respectivamente (HAFNER $\&$ SONS INCORPORATION, 2012). De acordo com a Secretaria de Infraestrutura Urbana da Prefeitura do Município de São Paulo (PMSP, 2012), observa-se um custo de $\mathrm{R} \$ 47,40 / \mathrm{m}^{3}$ associado ao agregado reciclado (e aqui em termos de agregados de classe A na resolução 307 do Conselho Nacional do Meio Ambiente - CONAMA, 2002), no caso de base (de pavimento) de material granular reciclado. O custo total do serviço de execução da base de pavimento com material reciclado é de $\mathrm{R} \$ 63,04 / \mathrm{m}^{3}$; o custo de uma base de brita graduada simples, de acordo com o mesmo referencial de custos unitários, é de $\mathrm{R} \$ 107,25 / \mathrm{m}^{3}$. Contudo, essa redução de $40 \%$ no custo não pode ser vista friamente sem uma análise de durabilidade dos materiais, de maneira comparativa. Acredita-se que, com base em preços operados nos mercados urbanos, respeitados os quesitos técnicos exigidos para os agregados, a redução de custos possa variar 
entre zero e $30 \%$. Ricci (2007) chegara a preços favoráveis, com redução de $36 \%$, em comparação às bases em bica corrida, empregando números das tabelas de preço da PMSP; o que evidencia que ocorreram movimentos não lineares nos ajustes dos preços ao longo de cinco anos.

Tais formações de custos são ainda muitas vezes apresentadas com composições não abertas por parte de produtores. Além disso, os processos de produção dos agregados reciclados a partir de resíduos de construção e de demolição não obrigatoriamente refletem o que de fato deve ser tido como procedimento no caso de reciclagem de pavimentos de concreto, não obstante pertencer ao grupo dos resíduos de classe A (CONAMA, 2002). Diante de questionamentos dessa natureza, julgou-se razoável a aferição em campo do processo de produção do agregado reciclado a partir de pavimentos de concreto existentes, bem como a composição de seu custo de produção, levando-se em conta as reais necessidades em termos de equipamentos de construção empregados e mão de obra requerida, conforme se expõe e se discute no presente estudo.

\section{ESTUDO DE PRODUTIVIDADE E CUSTOS NA RECICLAGEM DE PAVIMENTOS DE CONCRETO}

Nos estudos realizados foram tomadas as premissas básicas que são discutidas adiante, após coleta de dados presencial em pista e análises de alguns serviços de recuperação de pavimentos de concreto (com demolição de placas) realizados nos estados de Pernambuco e de São Paulo. Primeiramente, há que se afirmar que não há ainda uso cotidiano no país de equipamentos móveis para a reciclagem completa de placas de concreto in situ, incluindo sua demolição, britagem, classificação e nova usinagem de concretos empregando esses agregados reciclados. Essa tecnologia é já empregada há algumas décadas em países como os Estados Unidos da América (VANCURA et alli., 2010), Alemanha (HÖLLER, 2012), Áustria (VERIAN et alli., 2013) e outros países europeus (SCHIMMOLLER, 2000), mas o principal limitador do estudo desses equipamentos é a impossibilidade atual de aferição em pista, no Brasil, das horas produtivas e improdutivas de seus equipamentos e equipes, bem como os custos de aluguel, amortização, depreciação, etc., impedindo um cálculo abalizado, posto que não se dispõe de recicladoras de concreto in situ. Além disso, tais equipamentos de grande porte dificilmente seriam adaptáveis às condições urbanas, mormente considerada a geração de ruídos e suspensão de partículas que naturalmente causam.

De tal sorte que durante o trabalho investigativo dedicou-se a avaliar, em campo, a estrutura e sistemática de demolição com equipamentos de uso comum e generalizado no país, como os rompedores hidráulicos fixados em tratores. Para a análise de tais equipamentos foram realizadas medições em duas rodovias onde a demolição de placas, por razões diversas, estava em andamento, embora rodovias recém-construídas, cujas razões para serviços tão precoces de substituição de placas não são objeto de reflexão no presente artigo. Para tais estudos, contou-se com o apoio do Exército Brasileiro, no Estado do Pernambuco na BR101/PE, ao sul de Recife, nas cercanias do municio de Escada; no Estado de São Paulo, a Concessionária de Rodovias CCR apoiou os trabalhos, no Rodoanel Metropolitano Mário Covas, no município de Carapicuíba.
Para a composição de custos unitários é necessária a determinação das razões de produção unitárias dos itens de custo envolvendo os serviços. Segundo Souza (2012) “... quando se discute a produtividade, tanto em debates entre profissionais de campo ou especialistas quanto em artigos técnicos sobre o assunto, paira sempre uma grande dúvida sobre como foram calculados os indicadores que estão sendo utilizados." Nesse artigo são apresentados em detalhe os indicadores empregados para os cálculos de maneira que possam ser modificados e adaptados para situações diferentes daquelas analisadas presentemente, como base metodológica.

Existem três métodos básicos de estimativa da produção: (1) medição e aferição direta em campo, em obras específicas, para a finalidade de composição de preços; (2) metodologias ditas teóricas, como oferecidas pelo DNIT (2003); (3) consultas a especialistas para estabelecimento de padrões de produtividade. A questão da precisa determinação de índices de produtividade em obras é sempre matéria de discussões posto que ocorre atuação forte do Tribunal de Contas da União (2010) sobre as composições de custos unitários das obras rodoviárias, o que exige cautela e rigor na determinação dos parâmetros relacionados aos serviços, em especial quando a matéria é pouco conhecida, como é o caso da reciclagem de pavimentos de concreto.

\subsection{Processo de Produção de Agregados Reciclados avaliado em Rodovias}

O processo de demolição dos pavimentos de concreto existentes e avaliados empregou rompedores hidráulicos (pontaletes), fixados em tratores do tipo retroescavadeiras, que quebravam as placas em diversos pedaços que depois eram extraídos com emprego de uma pá-carregadeira (apresentada a sequência de demolição e transporte nas Figuras de 1 a 8 na sequência). Durante e após esta etapa de demolição os serventes retiram as barras (armaduras, barras de ligação e de transferência de cargas, etc.) soltas existentes. O material extraído era então depositado na caçamba de caminhão dumper trucado, que transporta o material ao destino final, que no caso do Rodoanel Metropolitano em São Paulo era a usina de britagem.

Em usina, o material de demolição é estocado, para o que se emprega uma pá-carregadeira. Para sua britagem, uma escavadeira hidráulica sobre esteiras alimenta diretamente a boca superior do britador de mandíbulas, que quebra todo o material usando processos de britagem primário e secundário (que exige a colocação do material primariamente já britado novamente no britador de mandíbula), levando o material granular às dimensões desejadas, bem como o classificando por diâmetros (peneiramento). O classificador recebe o material britado diretamente do britador por meio de uma esteira que o transporta. A sequência de produção é apresentada por meio das Figuras 9 a 16. Terminada esta operação, o agregado reciclado está pronto para emprego na construção civil. O material é estocado na usina, de modo classificado por diâmetros, sendo empregada a pá-carregadeira novamente para colocação das britas recicladas em caminhões para o destino final (uma usina de concreto, por exemplo). 
BALBO, J.T.; DORNELAS, R.C.

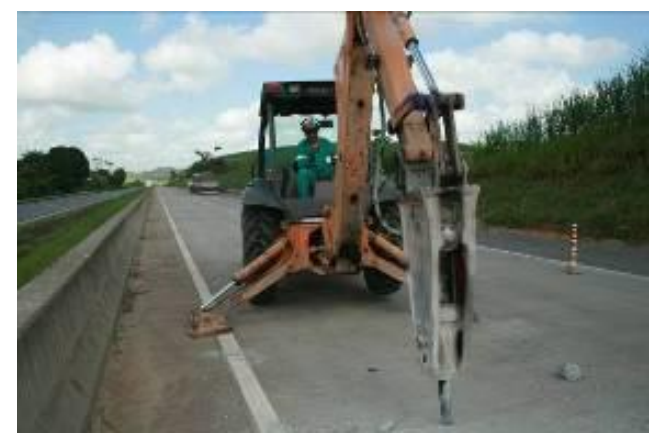

Figura 1- Início dos trabalhos de rompimento

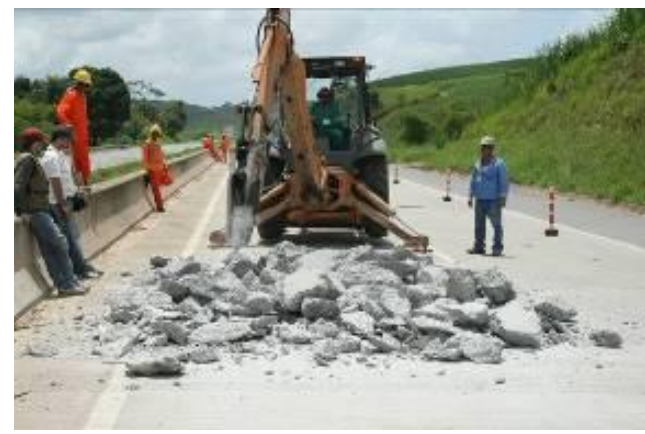

Figura 3- Avanço do trabalho de demolição

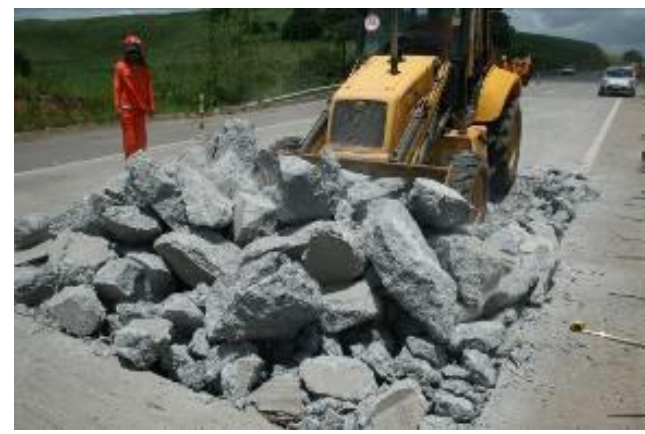

Figura 5- Coleta do resíduo

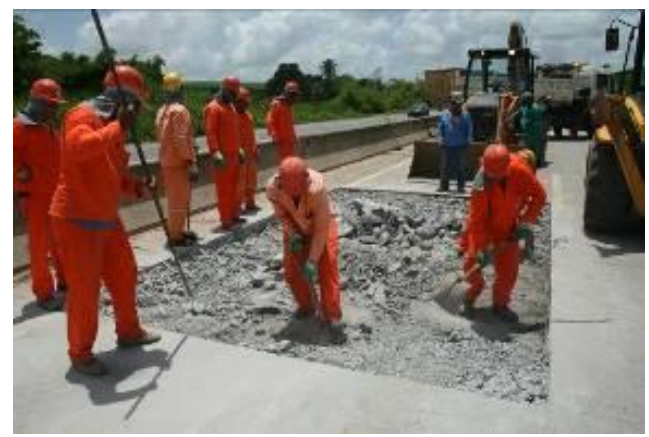

Figura 7- Coleta manual final do resíduo

\subsection{Quantificação do Processo de Produção nos Estudos de Casos}

A quantificação de equipamentos, equipes e tempos de produção foi realizada pela anotação de vários ciclos sucessivos das etapas de produção em seus respectivos locais de realização (pesquisa em campo). Na Tabela 2 são apresentados os detalhes de quantificação dos processos de produção e a determinação das razões unitárias de produção

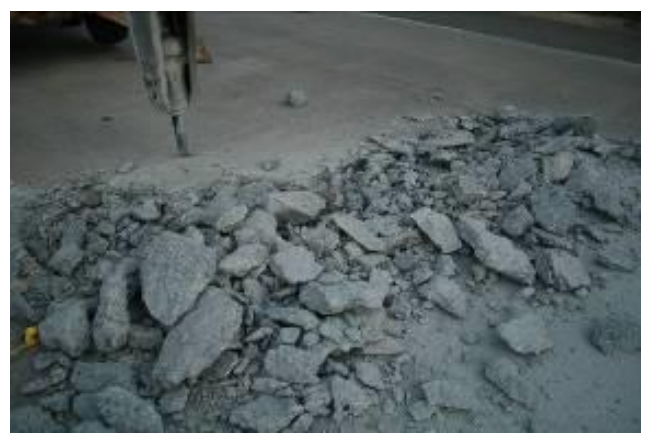

Figura 2- Desagregação superficial da placa

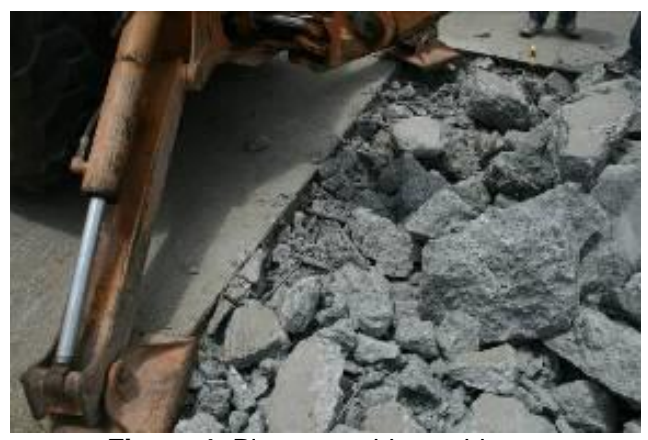

Figura 4- Placa rompida em blocos

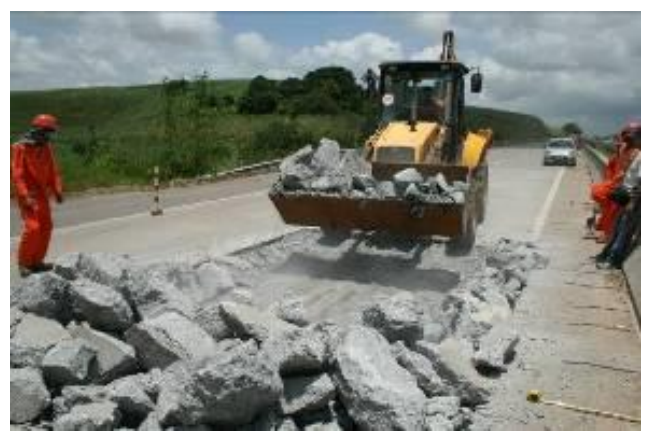

Figura 6 - Retirada do resíduo

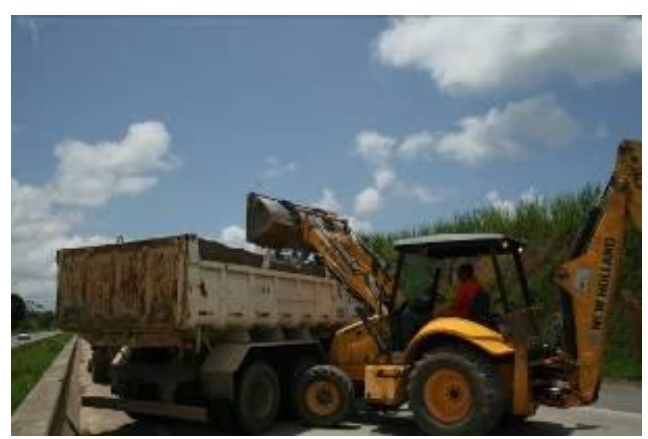

Figura 8- Carregamento do resíduo

(RPU's) para os serviços observados em pista. Os coeficientes de produção médios apresentados foram obtidos por observações sucessivas dos processos de demolição, carga e transporte dos pavimentos de concreto retirados de pista, realizados com equipamentos (patrulhas) semelhantes, na BR-101/PE (três dias de acompanhamento, 12 ciclos de transporte) em Pernambuco quanto no Rodoanel Metropolitano Mário Covas em São Paulo (dois dias de acompanhamento, 6 ciclos de transporte). 


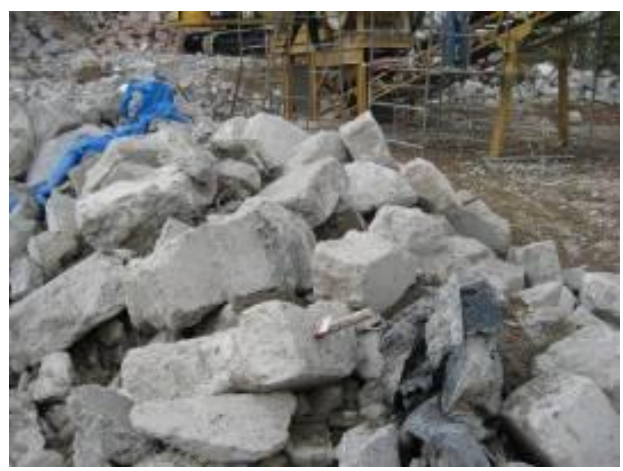

Figura 9- Blocos de concreto estocados

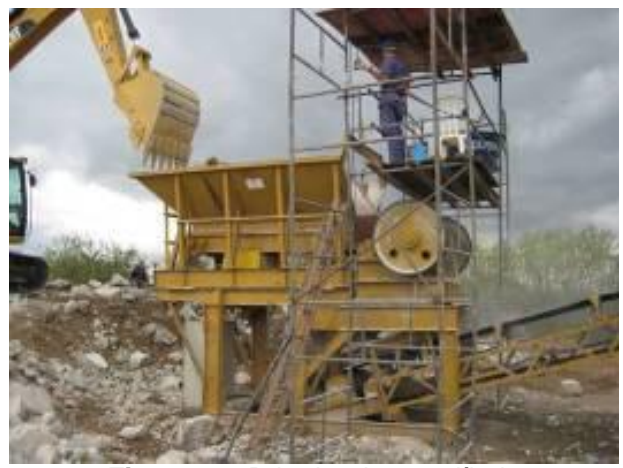

Figura 11- Britador de mandíbula

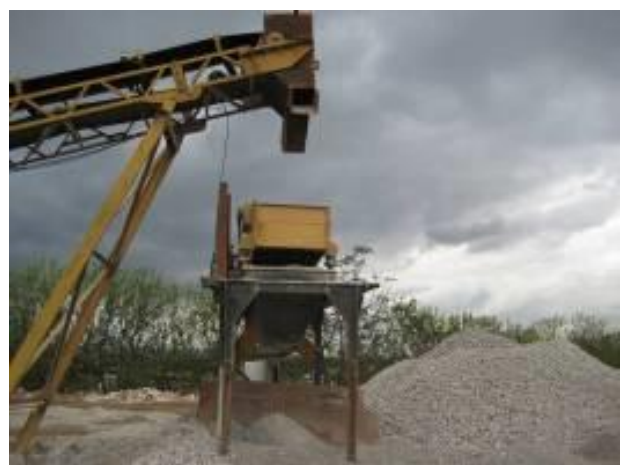

Figura 13- Classificação do material britado

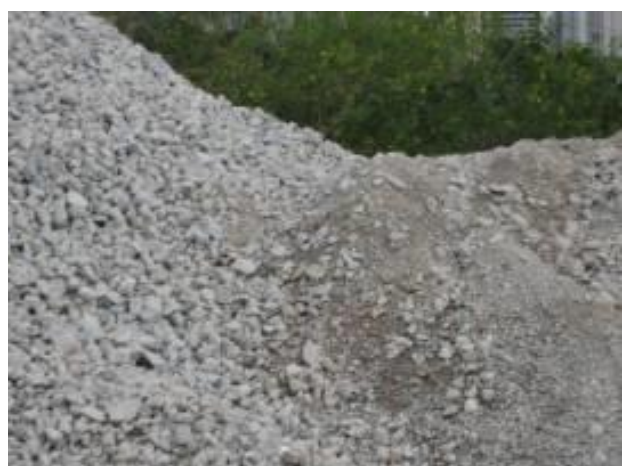

Figura 15- Resultado de britagem primária

\subsection{Estimativas de Custos para Produção de Agregados Reciclados a partir de Pavimentos de Concreto Simples}

Nas Tabelas 3 a 5 são apresentados, separadamente, os custos de demolição e carregamento de placas de concreto simples, de transporte e de britagem do concreto demolido para a produção de agregados, com base nos itens providos pelas tabelas de composição de custos do Sistema de Custos Rodoviários SICRO2 do Departamento Nacional

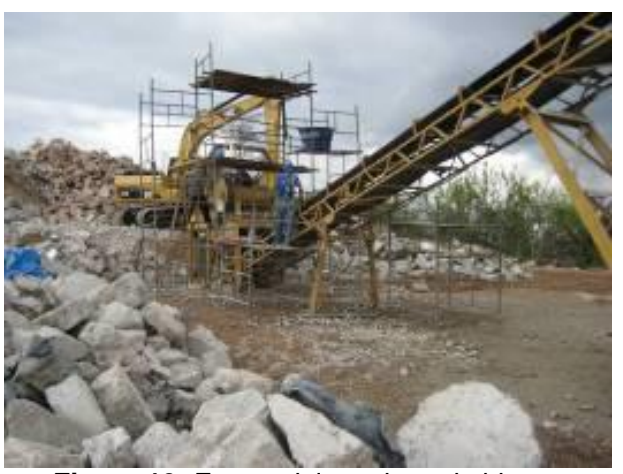

Figura 10- Escavadeira coletando blocos

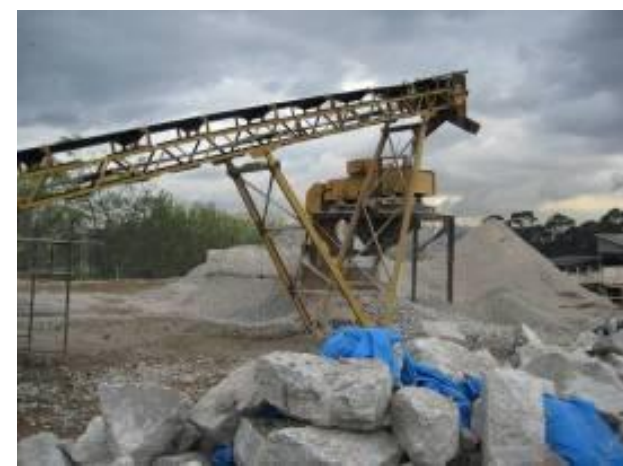

Figura 12- Esteira do britador

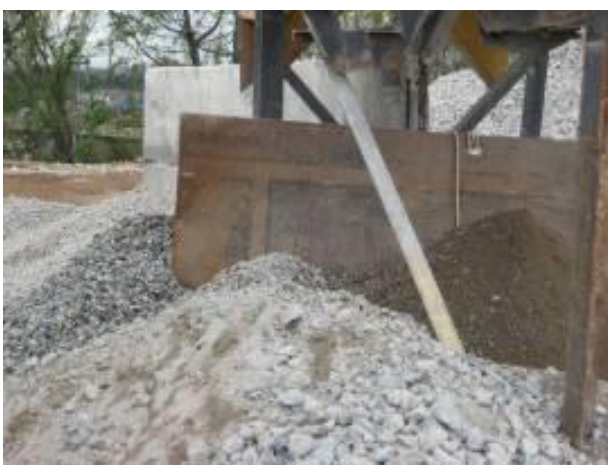

Figura 14- Material peneirado e separado

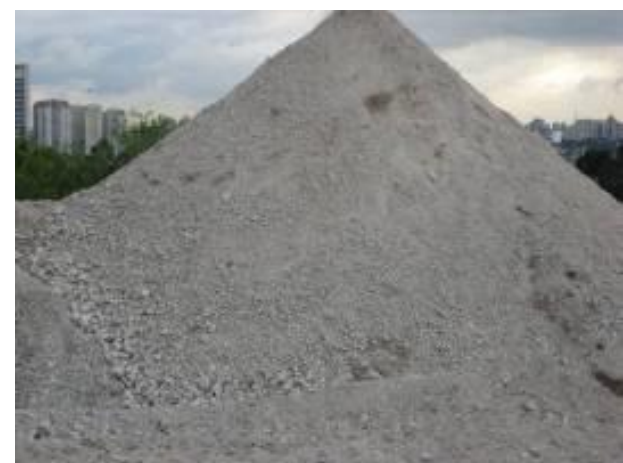

Figura 16- Resultado de britagem secundária

de Infraestrutura de Transportes (DNIT, 2011), para o mês de novembro de 2011 com valores referidos ao Estado de São Paulo. As razões de produção unitária foram, para os itens aplicáveis, ajustadas para as aferições obtidas em campo. As seguintes abreviações foram empregadas: utilização operativa (UO); utilização improdutiva (UI); custo horário operativo $(\mathrm{CHO})$; custo horário improdutivo $(\mathrm{CHI})$; custo horário $(\mathrm{CH})$; salário-hora $(\mathrm{SH})$; custo unitário $(\mathrm{CU})$; preço unitário (PU). 
BALBO, J.T.; DORNELAS, R.C.

Tabela 2. Quantificação dos serviços de produção e dos índices de produtividade

\begin{tabular}{l}
\hline Etapa \\
\hline \\
$\begin{array}{l}\text { Demolição de } \\
\text { placas e carga } \\
\text { do resíduo }\end{array}$
\end{tabular}
do resíduo

\section{Equipamentos empregados}

1 retroescavadeira com rompedor hidráulico;

1 pá-carregadeira, incluindo o operador.

Mão de obra produção

Rendimento do equipa-

mento $=0,92$;

Consome 40 minutos para romper uma placa de 6 × 3,6 m;

3 serventes

Espessura da placa $=22 \mathrm{~cm}$;

Rompe 10 placas por dia em $8 \mathrm{~h}$ de trabalho.

Transporte até 10 km de distância;

Velocidade média $=60 \mathrm{~km} / \mathrm{h}$;

Tempos variáveis e fixos $=10 \mathrm{~min}$ (ida) $+10 \mathrm{~min}$ (volta) +40 (carregamento pista)+20(descarrega-

Transporte dos resíduos de demolição de placas de concreto
1 caminhão trucado com motorista (inclusa) mento instalação de britagem); Capacidade do caminhão truncado $=10 \mathrm{~m}^{3}$;

5 ciclos completos por dia $(10 / 2=5$, abriga dois desmontes de placas ao mesmo tempo). Apenas um caminhão para uma equipe de desmonte. 2 sequências de britagens (primária e secundária);

A usina produz $66 \mathrm{~m}^{3} / \mathrm{h}$

1 escavadeira hidráulica com operador;

1 pá-carregadeira so-

Britagem dos resíduos de demolição bre pneus com operador;

1 britador de mandíbulas com esteira e classificador;

1 grupo gerador.
(SICRO2 A 01200 01);

A necessidade de produção é de $47,52 \mathrm{~m}^{3} \times 2$ (inclui a britagem primária e a britagem secundária) $=95,04 \mathrm{~m}^{3} / \mathrm{dia}$;

A usina empregará somente $95,04 \mathrm{~m}^{3} / 66 \mathrm{~m}^{3}=1 \mathrm{~h} 44$ de operação;

O conjunto opera $1 \mathrm{~h} 44$ (produtivas);

As demais horas da central são utilizadas para britar outros materiais
Cálculo das RUP's

Produção diária $=10 \times 6 \times 3,6$ x $0,22=47,52 \mathrm{~m}^{3}$ (10 placas);

Martelete hidráulico com operador $=8 / 47,52=$ $0,16835 \mathrm{~h} / \mathrm{m}^{3}$;

Serventes $=3$ homens $\times 8 \mathrm{~h} /$ $47,52 \mathrm{~m}^{3}=0,5051 \mathrm{~h} / \mathrm{m}^{3}$.

Produção diária de 10 placas rompidas $=47,52 \mathrm{~m}^{3}$;

Horas produtivas $=6 \mathrm{~h} 40=$ $6,666 \mathrm{~h}$;

Horas improdutivas $=$ $1 \mathrm{~h} 20=1,33 \mathrm{~h}$;

RUP prod. $=6,666 / 47,52=$ $0,1403 \mathrm{~h} / \mathrm{m}^{3}$;

RUP improd. $=1,33 / 47,52=$ $0,0281 \mathrm{~h} / \mathrm{m}^{3}$.

Produção diária atendida $=$ $47,52 * 2 \mathrm{~m}^{3} /$ dia em $1 \mathrm{~h} 44$ horas de operação; RUP produtiva $=0,0152$ $\mathrm{h} / \mathrm{m}^{3}$;

Escavadeira hidráulica com operador, RUP $=0,0152$ $\mathrm{h} / \mathrm{m}^{3}$;

Uma pá-carregadeira sobre pneus com operador, RUP = $0,0152 \mathrm{~h} / \mathrm{m}^{3}$;

Um britador de mandíbulas, RUP $=0,0152 \mathrm{~h} / \mathrm{m}^{3}$;

Um operador do britador, RUP $=0,0152 \mathrm{~h} / \mathrm{m}^{3}$;

Um servente, $\mathrm{RUP}=0,0152$ $\mathrm{h} / \mathrm{m}^{3}$.

Produção hor. $=149 \mathrm{~m}^{3} / \mathrm{h}$ 2 carregadeiras sobre pneus com operador, RUP produtiva $=(2 \mathrm{~h} \times 53 \%) / 149 \mathrm{~m}^{3}=$ $0,00711 \mathrm{~h} / \mathrm{m}^{3}$.

Produção de equipe de 149 $\mathrm{m}^{3} / \mathrm{h}$, usina dosadora - misturadora (SICRO2 1A0165601) pneus;

Produção de concreto com agregados virgens ou com agregados reciclados
1 central de concreto $180 \mathrm{~m}^{3} / \mathrm{h}$;

1 grupo gerador 288 $\mathrm{kVA}$
1 encarregado

6 serventes

Carregadeiras sobre pneus operam 53\% de uma hora (SICRO2 1A0165601)

Carregadeiras sobre pneus ficam inoperantes $47 \%$ de uma hora (SICRO2 1A0165601)
2 carregadeiras sobre pneus com operador, RUP improdutiva $=(2 \mathrm{~h} \times 47 \%) / 149 \mathrm{~m}^{3}=$ $0,00631 \mathrm{~h} / \mathrm{m}^{3}$;

1 central de concreto com operador, RUP=1h/149 $\mathrm{m}^{3}=$ $0,00671 \mathrm{~h} / \mathrm{m}^{3}$;

1 grupo gerador, $\mathrm{RUP}=1 \mathrm{~h} /$ $149 \mathrm{~m}^{3}=0,00671 \mathrm{~h} / \mathrm{m}^{3}$; 1 encarregado, $\mathrm{RUP}=1 \mathrm{~h} / 149$ $\mathrm{m}^{3}=0,00671 \mathrm{~h} / \mathrm{m}^{3}$; 6 serventes, RUP $=6 \mathrm{~h} / 149 \mathrm{~m}^{3}$ $=0,04027 \mathrm{~h} / \mathrm{m}^{3}$. 
Tabela 3. Composição de custo: remoção e carga de pavimentos de concreto simples (m3).

\begin{tabular}{|c|c|c|c|c|c|c|}
\hline A. Equipamento & Unid. & UO & $U \boldsymbol{I}$ & $\mathrm{CHO}(\mathrm{R} \$)$ & $\mathrm{CHI}(\mathrm{R} \$)$ & $C H(R \$)$ \\
\hline Escavadeira hidráulica com rompedor & $\mathrm{h}$ & 0,16835 & - & 180,00 & - & 30,30 \\
\hline E016 - Carregadeira de pneus - 1,91 m3 (113kW) & $\mathrm{h}$ & 0,16835 & - & 119,49 & - & 20,12 \\
\hline Custo Horário de Equipamentos & & & & & & 50,42 \\
\hline B. Mão de obra & Unid. & Coef. & & & SH & $\boldsymbol{C H}(\boldsymbol{R} \$)$ \\
\hline T701 - Servente & $\mathrm{h}$ & 0,5051 & & & 8,74 & 4,41 \\
\hline \multicolumn{6}{|l|}{ Adicional de Mão de Obra - Ferramentas $(20,51 \%)$} & 0,91 \\
\hline \multicolumn{6}{|l|}{ Custo Horário de Mao de Obra } & 5,32 \\
\hline \multicolumn{6}{|l|}{ Custo Unitário Total } & 55,74 \\
\hline
\end{tabular}

Tabela 4. Composição de custo: transporte de concreto demolido em pista (m3) Fonte: Xpto(2014)

\begin{tabular}{|c|c|c|c|c|c|c|}
\hline A. Equipamento & Unid. & $U \boldsymbol{O}$ & $U I$ & $C H O(R \$)$ & $C H I(R \$)$ & $C H(R \$)$ \\
\hline $\begin{array}{l}\text { E404 - Cam. Basculante } \\
10 \mathrm{~m}^{3}-15 \mathrm{t}(191 \mathrm{~kW})\end{array}$ & $\mathrm{h}$ & 0,1403 & 0,0281 & 128,45 & $\begin{array}{c}17,93 \\
\text { Custo Unitário Total }\end{array}$ & $\begin{array}{l}18,53 \\
\mathbf{1 8 , 5 3}\end{array}$ \\
\hline
\end{tabular}

Tabela 5. Composição de custo: britagem para produção dos agregados reciclados (m3)

\begin{tabular}{|c|c|c|c|c|c|c|}
\hline A. Equipamento & Unid. & $\boldsymbol{U O}$ & $U \boldsymbol{U}$ & $\mathrm{CHO}(\mathrm{R} \$)$ & CHI $(R \$)$ & $\boldsymbol{C H}(\boldsymbol{R} \$)$ \\
\hline E016-Carregadeira de pneus c/ 1,91 m³ $(113 \mathrm{~kW})$ & $\mathrm{h}$ & 0,01520 & - & 119,49 & - & 1,82 \\
\hline E225- Conjunto de britagem $\mathrm{p} / 80 \mathrm{~m}^{3} / \mathrm{h}(276 \mathrm{~kW})$ & $\mathrm{h}$ & 0,01520 & - & 470,24 & - & 7,15 \\
\hline E504-Grupo gerador de $288 \mathrm{kVA}(230 \mathrm{~kW})$ & $\mathrm{h}$ & 0,01520 & - & 128,24 & - & 1,95 \\
\hline E062-Escavadeira hidráulica s/ esteiras (200 kW) & $\mathrm{h}$ & 0,01520 & - & 269,31 & - & 4,09 \\
\hline \multicolumn{6}{|c|}{ Custo Horário de Equipamentos } & 15,01 \\
\hline B. Mão de obra & Unid. & Coef. & & & SH & $\boldsymbol{C H}(\boldsymbol{R} \$)$ \\
\hline T512-Encarregado de britagem & $\mathrm{h}$ & 0,01520 & & & 39,24 & 0,60 \\
\hline T701-Servente & $\mathrm{h}$ & 0,01520 & & & 8,74 & 0,13 \\
\hline \multicolumn{6}{|c|}{ Adicional de Mão de Obra - Ferramentas $(15,51 \%)$} & $\mathbf{0 , 1 1}$ \\
\hline \multicolumn{6}{|c|}{ Custo Horário de Mao de Obra } & 0,84 \\
\hline \multicolumn{6}{|c|}{ Custo Unitário de Execução } & 15,85 \\
\hline C. Serviços Diversos & Unid. & Coef. & & & $\overline{P U}$ & $\boldsymbol{C U}(\boldsymbol{R} \$)$ \\
\hline 1A0096300-Peças de desgaste do britador & cj. & 0,01520 & & & 137,63 & 2,09 \\
\hline \multirow{2}{*}{\multicolumn{6}{|c|}{$\begin{array}{r}\text { Custo Total das Atividades Auxiliares } \\
\text { Custo Unitário Total }\end{array}$}} & 2,09 \\
\hline & & & & & & 17,94 \\
\hline
\end{tabular}

Desta forma, ao somar-se os custos unitários de demolição e carga, transporte e britagem dos agregados reciclados, o custo unitário estimado para eles é de R \$ 92,21 por metro cúbico. Para a PMSP (2012), o custo unitário de pedra britada 2 é de $\mathrm{R} \$ 62,93 / \mathrm{m}^{3}$; para pedras britadas 3 e 4 é de $\mathrm{R} \$ 66,11 / \mathrm{m}^{3}$; pedra britada de $1 / 2$ " tem custo de $\mathrm{R} \$ 64,78$ e pó de pedra de $\mathrm{R} \$ 67,06$; pedra 1 de $\mathrm{R} \$ 64,04$; pedra 2 de $\mathrm{R} \$ 62,35$; pedrisco de $\mathrm{R} \$ 66,97$. Portanto, chegase a custo de 1,5 vezes superior ao do agregado virgem.

\subsection{Estimativas de Custo de Produção de Concretos para Pavimentação}

Para finalidades de estimativa dos custos de produção do agregado e do concreto reciclado foram empregados os critérios e índices de produtividade anteriormente apresentados para a britagem do concreto. Contudo, a reciclagem do concreto pode exigir (e normalmente exige) a substituição de parte dos agregados miúdos reciclados (excesso de argamassa moída e porosa) por agregados miúdos virgens, como garantia de qualidade do concreto reciclado. Considerou-se então na composição de custos a situação de reciclagem com emprego de $50 \%$ de agregados virgens na fração miúda, para a composição do concreto reciclado, mantida a reciclagem de $100 \%$ dos agregados graúdos. Na Tabela 6 e 7 são apresentados os traços dos concretos empregados na pesquisa de Tseng (2010) para finalidades de elaboração dos custos de fornecimento desses concretos para pavimentação de novas placas de concreto (recicladas), dadas as características de resistência e demais parâmetros mecânicos observados durante a elaboração da pesquisa. As placas de concreto removidas do Rodoanel Metropolitano Mário Covas em São Paulo foram britadas para estudos de dosagem, chegando-se aos valores indicados para a reposição de concreto cuja resistência de dosagem fosse de $5 \mathrm{MPa}$ (à tração na flexão), com os agregados reciclados, ou mesmo com agregados virgens (concreto absolutamente novo), para estudos comparativos.

Os preços de fornecimento de materiais para a fabricação dos concretos foram estabelecidos com base nas tabelas do sistema de custos SICRO2 (DNIT, 2011), referidos ao mês de novembro de 2011, para São Paulo. Tais preços encontram-se na Tabela 8 para o concreto convencional com agregados virgens. Na Tabela 9 são indicados os preços para o concreto reciclado (sendo que esta última faz adaptação do SICRO2 com os traços de concreto fornecidos por Tseng, 2010).

\section{DISCUSSÃO SOBRE OS CUSTOS DE CONCRETOS RECICLADOS}

Antes de discutir propriamente os resultados obtidos é razoável considerar que, as massas unitárias têm impacto importante nos indicadores e nos preços finais calculados para os concretos; procurou-se empregar valores dentro de faixa razoável para os concretos estudados. Os cálculos de custos unitários resultaram em custos de produção dos concretos com agregados reciclados a partir de pavimentos de concreto preexistentes superiores àqueles de produção de concretos tradicionais. Na Tabela 10 são expostas as dife- 
BALBO, J.T.; DORNELAS, R.C.

Tabela 6. Traços de concretos para determinação de custos unitários (kg).

\begin{tabular}{|c|c|c|c|c|c|}
\hline Concreto & $\begin{array}{l}\text { Cimento } \\
(\mathrm{kg})\end{array}$ & $\begin{array}{l}\text { Agregado } \\
\text { Graúdo } \\
(\mathrm{kg})\end{array}$ & $\begin{array}{l}\text { Agregado Miúdo } \\
(\mathrm{kg})\end{array}$ & $\begin{array}{l}\text { Água } \\
(\mathrm{kg})\end{array}$ & $\begin{array}{l}\text { Massa específica } \\
\left(\mathrm{kg} / \mathrm{m}^{3}\right)\end{array}$ \\
\hline Convencional & 374 & 1.167 & 665 & 182 & 2.399 \\
\hline $\begin{array}{l}\text { Reciclado com agregados } \\
\text { Reciclados do Rodoanel (SP) }\end{array}$ & 353 & 943 & $\begin{array}{l}297 \text { (reciclado) } \\
297 \text { (virgem) }\end{array}$ & 232 & 2.265 \\
\hline
\end{tabular}

renças mais prementes das composições de custo apresentadas. Observa-se que o custo do agregado reciclado, tomado o processo de reciclagem analisado nessa pesquisa, é preponderante para o incremento de aproximadamente $19 \%$ no custo final do concreto.

Uma análise mais detalhada do ponto de vista de sustentabilidade deverá, futuramente, levar em consideração os passivos energéticos na fabricação dos materiais para uma comparação considerando-se os quantitativos de emissões de $\mathrm{CO}_{2}$. Este trabalho tem caráter preliminar e não buscou quantificar os custos ambientais relacionados à escavação de jazidas de agregados, seu transporte, bem como a emissão de $\mathrm{CO}_{2}$ devida a cada caso. Somente à luz dessa fronteira é que se poderão estimar, ao menos para grandes obras com relevante impacto ambiental, quais as reais vantagens econômicas do uso de agregados reciclados de pavimentos de concreto deteriorados para a confecção de novos pavimentos de concreto.

Retomando-se a Tabela 1 podem ser calculados os potenciais econômicos tanto de produção de agregados reciclados a partir da demolição dos pavimentos de concreto (passíveis de demolição) no Brasil, o que é apresentado na Tabela 11 (base de preços SICRO2, novembro de 2011, São Paulo). Os resultados indicam que, em termos de mercado, poderia existir pouco interesse no processo, consideradas suas dificuldades tecnológicas (em especial transporte para usina de britagem e posterior estocagem dos agregados reciclados); talvez os apelos técnicos e ambientais não suplantem tais limitações, que poderiam ser vencidas com o emprego da reciclagem específica in situ para a reconstrução dos pavimentos de concreto; contudo temos de ter a lhaneza de considerar que reciclagem in situ de pavimentos de concreto depende do emprego de equipamentos móveis de pista, altamente tecnológicos, de elevadíssimo custo, para o pequeno montante volumétrico de pavimentos de concreto rodoviários (excluídos os urbanos onde recicladoras móveis de grande porte não transitam).

\section{CONCLUSÕES E CONSIDERAÇÕES FINAIS}

Estudou-se o processo de demolição de pavimentos de concreto e sua reciclagem para a produção de agregados em usina de britagem, tendo sido realizada aferição de produção em pista, em duas rodovias brasileiras; isso permitiu a determinação das razões de produção unitárias abalizadas. A determinação dos custos de produção dos agregados reciclados a partir de tais insumos resultou em aumento do custo de fornecimento, segundo metodologia oficial do DNIT, em cerca de 50\%, em comparação aos preços de agregados virgens operados pela Secretaria de Infraestrutura Urbana da PMSP.

Tabela 7. Traços de concretos para determinação de custos unitários (m3).

\begin{tabular}{llllll}
\hline Concreto & $\begin{array}{l}\text { Cimento } \\
(\mathbf{k g})\end{array}$ & $\begin{array}{l}\text { Agregado Graúdo } \\
(\mathbf{m 3})\end{array}$ & $\begin{array}{l}\text { Agregado Miúdo } \\
(\mathbf{m 3})\end{array}$ & $\begin{array}{l}\text { Água } \\
(\mathbf{k g})\end{array}$ & $\begin{array}{l}\text { Massa específica } \\
(\mathbf{k g} / \mathbf{m 3})\end{array}$ \\
\hline Convencional & 374 & 0,6865 & 0,4130 & 182 & 2.399 \\
Reciclado com agregados & 353 & 0,5547 & $\begin{array}{l}0,1980 \text { (reciclado) } \\
0,1845 \text { (virgem) }\end{array}$ & 232 & 2.265 \\
Reciclados do Rodoanel (SP) & & & & & \\
\hline
\end{tabular}

Tabela 8. Composição de custo: usinagem do concreto fct, $f=5 \mathrm{MPa}$ com agregados virgens, por m3, com produção de equipe de $149 \mathrm{~m} 3$ (SICRO2 1A0165601).

\begin{tabular}{|c|c|c|c|c|c|c|}
\hline A. Equipamento & Unid. & $U \boldsymbol{O}$ & $\boldsymbol{U I}$ & $\mathrm{CHO}(\mathrm{R} \$)$ & $C H I(R \$)$ & $C H(R \$)$ \\
\hline E010-Carregadeira de pneus $\left(3,3 \mathrm{~m}^{3} ; 147 \mathrm{~kW}\right)$ & $\mathrm{h}$ & 0,00711 & 0,00631 & 208,05 & 19,62 & 1,604 \\
\hline E335-Central de concreto $\left(180 \mathrm{~m}^{3} / \mathrm{h} ; 149 \mathrm{~kW}\right)$ & $\mathrm{h}$ & 0,00671 & 0,00 & 356,40 & 20,74 & 2,392 \\
\hline E504-Grupo gerador de $288 \mathrm{kVA}(230 \mathrm{~kW})$ & $\mathrm{h}$ & 0,00671 & 0,00 & 128,24 & 15,13 & 0,861 \\
\hline Custo Horário de Equipamentos & & & & & & 4,856 \\
\hline B. Mão de obra & Unid. & Coef. & & & SH & $\mathrm{CH}(\boldsymbol{R} \$)$ \\
\hline T501 - Encarregado de turma & $\mathrm{h}$ & 0,00671 & & & 24,66 & 0,166 \\
\hline T701 - Servente & $\mathrm{h}$ & 0,04027 & & & 8,74 & 0,352 \\
\hline Adicional de Mão de Obra - Ferramentas $(20,51 \%)$ & & & & & & 0,106 \\
\hline Custo Horário de Mao de Obra & & & & & & 0,624 \\
\hline Custo Unitário de Execução & & & & & & 5,48 \\
\hline C. Material & Unid. & Qtdade. & & & $P U$ & $\boldsymbol{C U}(\boldsymbol{R} \$)$ \\
\hline M201 - Cimento Portland CP32 (a granel) & $\mathrm{kg}$ & 374,00 & & & 0,47 & 175,78 \\
\hline M604 - Aditivo plastificante & $\mathrm{kg}$ & 0,7480 & & & 1,96 & 1,47 \\
\hline Custo Total de Materiais & & & & & & 177,25 \\
\hline D. Atividades Auxiliares & Unid. & Qtdade. & & & $P U$ & $C U(R \$)$ \\
\hline Agregado Miúdo - MAES $=1.610 \mathrm{~kg} / \mathrm{m}^{3}$ & $\mathrm{~m}^{3}$ & 0,4130 & & & 6,03 & 2,49 \\
\hline Agregado Graúdo - MAES $=1.700 \mathrm{~kg} / \mathrm{m}^{3}$ & $\mathrm{~m}^{3}$ & 0,6865 & & & 27,68 & 19,00 \\
\hline Custo Total das Atividades Auxiliares & & & & & & 21,49 \\
\hline Custo Unitário Total & & & & & & 204,22 \\
\hline
\end{tabular}


Tabela 9. Composição de custo: usinagem do concreto fct, $f=5 \mathrm{MPa}$ com agregados reciclados, por m3, com produção de equipe de $149 \mathrm{~m} 3$.

\begin{tabular}{|c|c|c|c|c|c|c|}
\hline A. Equipamento & Unid. & UO & UI & $\mathrm{CHO}(\mathrm{R} \$)$ & CHI $(R \$)$ & $C H(R \$)$ \\
\hline E010-Carregadeira de pneus $\left(3,3 \mathrm{~m}^{3} ; 147 \mathrm{~kW}\right)$ & $\mathrm{h}$ & 0,00711 & 0,00631 & 208,05 & 19,62 & 1,604 \\
\hline E335-Central de concreto $\left(180 \mathrm{~m}^{3} / \mathrm{h} ; 149 \mathrm{~kW}\right)$ & $\mathrm{h}$ & 0,00671 & 0,00 & 356,40 & 20,74 & 2,392 \\
\hline E504-Grupo gerador de $288 \mathrm{kVA}(230 \mathrm{~kW})$ & $\mathrm{h}$ & 0,00671 & 0,00 & 128,24 & 15,13 & 0,861 \\
\hline Custo Horário de Equipamentos & & & & & & 4,856 \\
\hline B. Mão de obra & Unid. & Coef. & & & SH & $\mathrm{CH}(\mathrm{R} \$)$ \\
\hline T501 - Encarregado de turma & $\mathrm{h}$ & 0,00671 & & & 24,66 & 0,166 \\
\hline T701 - Servente & $\mathrm{h}$ & 0,04027 & & & 8,74 & 0,352 \\
\hline Adicional de Mão de Obra - Ferramentas (20,51\%) & & & & & & 0,106 \\
\hline Custo Horário de Mao de Obra & & & & & & 0,624 \\
\hline Custo Unitário de Execução & & & & & & 5,48 \\
\hline C. Material & Unid. & Qtdade. & & & $P U$ & $C U(R \$)$ \\
\hline M201 - Cimento Portland CP32 (a granel) & $\mathrm{kg}$ & 353,00 & & & 0,47 & 165,91 \\
\hline M604 - Aditivo plastificante & $\mathrm{kg}$ & 0,71 & & & 1,96 & 1,38 \\
\hline Custo Total de Materiais & & & & & & 167,29 \\
\hline D. Atividades Auxiliares & Unid. & Qtdade. & & & $P U$ & $C U(R \$)$ \\
\hline Agregado Graúdo Reciclado MAES $=1.700 \mathrm{~kg} / \mathrm{m}^{3}$ & $\mathrm{~m}^{3}$ & 0,5547 & & & 92,21 & 51,15 \\
\hline Agregado Miúdo Reciclado MAES $=1.500 \mathrm{~kg} / \mathrm{m}^{3}$ & $\mathrm{~m}^{3}$ & 0,1980 & & & 92,21 & 18,26 \\
\hline Agregado Miúdo (virgem) MAES $=1.500 \mathrm{~kg} / \mathrm{m}^{3}$ & $\mathrm{~m}^{3}$ & 0,1845 & & & 6,03 & 1,11 \\
\hline Custo Total das Atividades Auxiliares & & & & & & 70,52 \\
\hline Custo Unitário Total & & & & & & 243,29 \\
\hline
\end{tabular}

Tabela 10. Comparação entre as composições de custos de produção de concretos

\begin{tabular}{llll}
\hline Concreto & Convencional & Reciclado & $\boldsymbol{\Delta}(\boldsymbol{\%})$ \\
\hline Custo total $(\mathrm{R} \$)$ & 204,22 & 243,29 & $\sim 19$ \\
\hline Agregado graúdo $(\mathrm{R} \$)$ & 19,00 & 51,15 & $\sim 169$ \\
\hline Agregado miúdo $(\mathrm{R} \$)$ & 2,49 & 19,37 & $\sim 678$ \\
\hline
\end{tabular}

Tabela 11. Potencial econômico no Brasil de rodovias pavimentadas em concreto para produção de agregados reciclados.

\begin{tabular}{|c|c|c|c|}
\hline Estado & $\begin{array}{l}\text { Potencial econômico } \\
\text { (milhóes de } R \$ \text { ) }\end{array}$ & Cidade & $\begin{array}{l}\text { Potencial econômico } \\
\text { (milhoes de } \boldsymbol{R} \$ \text { ) }\end{array}$ \\
\hline Pernambuco & 33,9 & Recife & 22,2 \\
\hline Bahia & 1,9 & Belo Horizonte & 0,027 \\
\hline Mato Grosso & 3,8 & Rio de Janeiro & 1,06 \\
\hline Rio de Janeiro & 15,2 & Curitiba & 4,8 \\
\hline São Paulo & 50,7 & Porto Alegre & 3,9 \\
\hline Santa Catarina & 1,2 & & \\
\hline Rio Grande do Sul & 5,5 & & \\
\hline Total & 112,20 & Total & 31,99 \\
\hline
\end{tabular}

O custo final do concreto produzido com agregados reciclados de antigos pavimentos de concreto superou em $19 \%$ o custo de produção de concretos convencionais para as condições de distância de transporte consideradas $(10 \mathrm{~km}$ de distância entre pista e usina de britagem), específica para o estudo desenvolvido. Tais valores sugerem maiores custos de produção; de forma oposta, na literatura estrangeira são comumente encontrados cálculos e opiniões favoráveis, indicando redução de custos na produção de pavimentos de concreto reciclados. Essas conclusões externas não refletem o atual estado da arte no Brasil, onde os processos de produção dependem do transporte do material demolido, às vezes em longas distâncias, não sendo realizada a reciclagem in situ.

O potencial econômico de reciclagem dos pavimentos de concreto no Brasil, dadas as limitações de tecnológicas apontadas, somadas ao fato de existir pouca extensão disponível de rodovias em concreto no Brasil, é relativamente baixo (algo em torno de R $\$ 150$ milhões), podendo ser um fator de mercado que não conduza ao avanço do emprego do material reciclado da melhor maneira em termos de sustentabilidade, que seria "fazer do velho o novo": um pavimento novo a partir daquele demolido.

\section{REFERÊNCIAS}

American Concrete Pavement Association (2009) Recycling concrete pavements. Skokie.

Associação Brasileira de Cimento Portland (2009) O concreto pavimentando os caminhos na formação de um novo país. São Paulo.

Balbo, J.T. (2009) Pavimentos de concreto. Oficina de Textos, São Paulo.

Confederação Nacional dos Transportes (2014) Pesquisa CNT de Rodovias 2014. Relatório Gerencial. CNT/SEST/SENAT, Brasília. Disponível em: pesquisarodovias.cnt.org.br/. Acesso em: 18.04.2015.

Conselho Nacional do Meio Ambiente (2002) Resolução no. 307. Brasília.

Darter, M. I. (1988) Initial evaluation of Michigan JRCP crack deterioration. Michigan Concrete Paving Association, Lansing. 
Departamento Nacional De Infraestrutura de Transportes (2003) Manual de custos rodoviários - Metodologia e conceitos. $3^{\mathrm{a}}$. edição, v.1, Rio de Janeiro.

Departamento Nacional De Infraestrutura de Transportes (2011) Manual de custos rodoviários - Metodologia e conceitos. $3^{\mathrm{a}}$. edição, v.1, Rio de Janeiro.

Departamento Nacional de Infraestrutura De Transportes (2012). Rede sob jurisdição federal - versão 2012. Ministério dos Transportes, DNIT-DPP/CG PLAN/Coordenação de Planejamento, Brasília. Disponível em: dnit.gov.br/planejamento-e-pesquisa/planejamento/evolucao-da-malha-rodoviaria/snv2014-jurisdicao federal.pdf. Acesso em: 28/12/2012.

Portland Cement Association (1999) Recycling concrete and masonry. EV.22, Skokie.

Hafner \& Sons Incorporation (2012) Cincinnati Recycled Aggregate. Disponível em: www.hafners.com /cincinnatilandscaping-supplies/recycled-aggregates.html. Acesso em: 26.04.2013).

Hall, K. (2007) Long-life concrete pavements in Europe and Canada. Federal Highway Administration Publication FHWA$P L-07-027$, Washington D.C.

Höller, S. (2012) Concrete Pavement Design and Construction in Germany - State of the Art. In: XVI Congreso Argentino de Vialidad y Transito, Cd-rom, Cordoba.

Prefeitura do Município de São Paulo (2012) Tabelas de Custos. Secretaria Municipal de Infraestrutura Urbana e Obras da Prefeitura do Município de São Paulo. Disponível em:www.prefeitura.sp.gov.br/cidade/secretarias/infraestrutura/ta

belas_de_custos/index.php?p=47729. Acesso em: 29.04.2013.

Ricci, G. (2007) Estudo de Características Mecânicas do Concreto Compactado com Rolo com Agregados Reciclados de Construção e de Demolição para Pavimentação. Dissertação (Mestrado), Programa de Pós-Graduação em Engenharia de Transportes, Escola Politécnica, Universidade de São Paulo, São Paulo.

Souza, U. L. S. (2012) Como medir a produtividade da mão-deobra na Construção Civil. Universidade Federal da Bahia. Disponível em: www.gerenciamento.ufba.br/Disciplinas/Produtivid ade/.

Tseng, E. (2010) Reciclagem total de pavimentos de concreto como agregados para construção de novos pavimentos de concreto: o caso do Rodoanel Metropolitano Mário Covas. Dissertação (Mestrado), Programa de Pós-Graduação em Engenharia de Transportes, Escola Politécnica da Universidade de São Paulo, São Paulo.

Schimmoller, V. E. et alli. (2000) Recycled Materials in European Highway Environments: Uses, Technologies, and Policies. U.S. Department of Transportation, Federal Highway Administration, International Technology Exchange Program, Washington, D.C.

Snyder, M. B. et al. (1997) Physical and mechanical properties of recycled PCC aggregate concrete. Federal Highway Administration, U.S. Department of Transportation, Report DTFH61-93-C00133, Washington D.C.

Tseng, E.; Balbo, J.T. (2013) Reciclagem de pavimentos de concreto: equipamentos, processos e o potencial de reciclagem no
Brasil. In: $55^{\circ}$. Congresso Brasileiro do Concreto, Instituto Brasileiro do Concreto, Gramado.

Tribunal de Contas da União (2010) Licitações \& Contratos. Orientações e Jurisprudência do TCU. $4^{\text {a }}$. edição revista, atualizada e ampliada. TCU e Senado Federal, Brasília.

United States Department of Transportation (2004) Transportation Applications of Recycled Concrete Aggregate. Federal Highway Administration State of the Practice National Review, Washington, D.C.

Vancura, M.E.; Tompkins, D.; Khazanovich, L. (2010) PCC Mix Designs Using Recycled Concrete Pavements. In: 21st Annual Transportation Research Conference, Saint Paul.

Verian, K.P.;Whiting, N. M.; Olek, Jan,J.; Jain, J.; Snyder, M.B. (2013) Using Recycled Concrete as Aggregate in Concrete Pavements to Reduce Materials Cost. Joint Transportation Research Program, Purdue University, FHWA/IN/JTRP-2013/18, West Lafayette.

Yrjanson, W. A. (1989) Recycling of Portland cement concrete pavements. Transportation Research Board, National Research Council, NCHRP Synthesis 154, Washington, D.C.

Wolf, T.E.; Fleischer, W. (2007) Moderner Betonstraßenbau aus Deutschland. In: International Conference on Concrete Roads, Cd-rom, Bratislava. 